Rhode Island College

Digital Commons @ RIC

2017

\title{
An Exploration of Potential Gender Differences in the Discipline of Nurse Anesthetists
}

Jedidiah F. Kane

Follow this and additional works at: https://digitalcommons.ric.edu/etd

Part of the Other Nursing Commons

\section{Recommended Citation}

Kane, Jedidiah F., "An Exploration of Potential Gender Differences in the Discipline of Nurse Anesthetists" (2017). Master's Theses, Dissertations, Graduate Research and Major Papers Overview. 255.

https://digitalcommons.ric.edu/etd/255

This Major Paper is brought to you for free and open access by the Master's Theses, Dissertations, Graduate Research and Major Papers at Digital Commons @ RIC. It has been accepted for inclusion in Master's Theses, Dissertations, Graduate Research and Major Papers Overview by an authorized administrator of Digital Commons @ RIC. For more information, please contact digitalcommons@ric.edu. 


\title{
AN EXPLORATION OF POTENTIAL GENDER DIFFERENCES \\ IN THE DISCIPLINE OF NURSE ANESTHETISTS
}

\author{
by \\ Jedidiah F. Kane, BSN, SRNA \\ A Major Paper Submitted in Partial Fulfillment \\ of the Requirements for the Degree of \\ Master of Science in Nursing \\ in \\ The School of Nursing \\ Rhode Island College \\ 2017
}




\begin{abstract}
Great diversity exists in the US population, therefore the US Department of Health and Human Services [HHS] has called for increased diversity among healthcare professionals as a means of improving public health outcomes. Males are consistently a minority group within the nursing profession and are disproportionately disciplined. The disproportionate discipline of male nurses and the loss of licensure often resulting from censure may have an impact on efforts to diversify the nursing sector of healthcare. Among certified registered nurse anesthetists [CRNAs], the ratio of males to females is more equal and little data exists examining the characteristics of disciplined CRNAs. The purpose of this study was to describe formal licensure discipline against CRNAs practicing in select states during a 33-year period (1983-2017). This descriptive study is a retrospective cohort study involving secondary data analysis of public records information.

Disciplinary list data was generated via the database tools accessible on the government websites provided by each state department of health and/or BON. The disciplinary list data was then cross-referenced against the Nursys database maintained by the National Council of State Boards of Nursing (NCSBN) for greater detail and analysis. Of the CRNA licenses in the sample $(n=4401)$, the rate of sanction was $1.20 \%(n=53)$. Males $(n=26)$ were disciplined more often than women $(n=27)$ at a ratio of 1.6:1. CRNAs in this study were six times more likely to commit an infraction related to substance abuse than any other single infraction type at $66 \%(n=35)$. Loss of licensure in some form resulted in approximately $51 \%(n=27)$ of cases.
\end{abstract}




\section{Table of Contents}

Background/Statement of the Problem .................................................................. 1

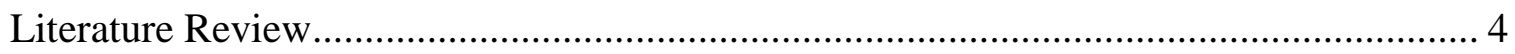

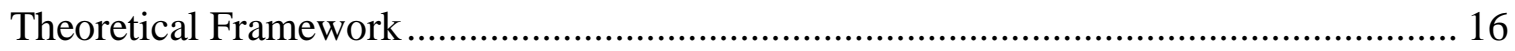

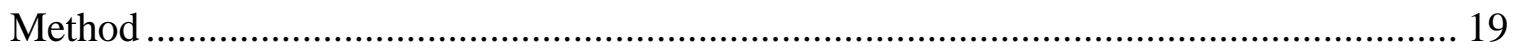

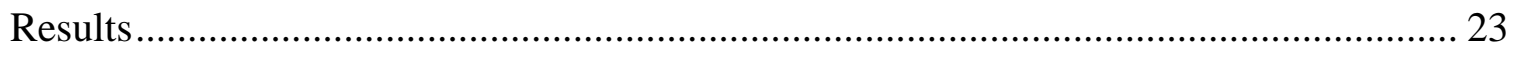

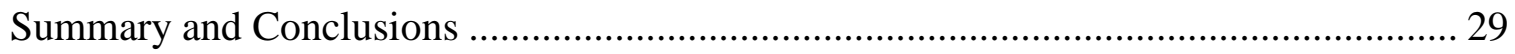

Recommendations and Implications for Advanced Nursing Practice ........................... 33

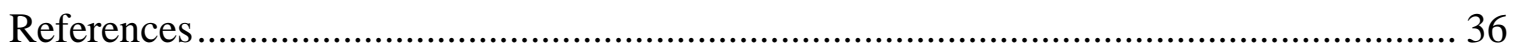


An Exploration of Potential Gender Differences in The Discipline of Nurse Anesthetists

\section{Background/Statement of the Problem}

Diversity in the modern work place, defined as variation in organizational demographics such as age, race, ethnicity and gender, has been documented as beneficial and is increasingly viewed as crucial in relation to market share, networking, staff recruitment, innovation, overall business image and civil rights compliance (Carter, Simkins, \& Simpson, 2003; Lockwood, 2005; Parker, Stack, Schneider, \& Summit, 2017; Roberson \& Park, 2007; Thomas, 2004). In healthcare, these benefits potentially impact patient satisfaction, interdisciplinary collaboration, staff recruitment, research/evidence based practice, confidence of the public and cultural competence. Health care in the United States (US), which serves a diverse population and represents a large professional sector, has a special need for diversity of workforce (US Department of Health and Human Services [HHS], 2006). There exist a number of relevant studies linking diversity in both the patient population and in the healthcare workforce to public health outcomes. Two such studies are The rationale for diversity in the health professions: A review of the evidence and National Healthcare Disparities Report: 2011, both of which call for increased diversity in healthcare professionals as a means of improving public health (US

Department of Health and Human Services [HHS], 2006; 2011). Nursing in particular, which is simultaneously the most populous profession in healthcare (National Center for Health Workforce Analysis [NCHWA], 2015) and the sector enjoying the most direct contact with the diverse public being served (Benner et al., 2006; HHS, 2006; Thomas, 2010), exemplifies this need and has actively pursued diversity among its ranks over the course of its history (American Association of Colleges of Nursing [AACN], 2015). 
However, despite this noteworthy aim and its accompanying gains, areas of severe underrepresentation persist (Budden, Zhong, Moulton, \& Cimiotti, 2013).

One such underrepresented group has been that of men (Budden et al.). According to the NCHWA, males have recently characterized roughly $9.2 \%$ of the professional nursing populous (2015), marking a significant increase from just 5\% in years prior to 2000 (Budden et al., 2013). Males find their largest numbers in the nurse anesthesia specialty of advance practice nursing (US Census Bureau [USCB], 2013; American Association of Nurse Anesthetists [AANA], 2015). According to the AANA, males represent greater than $40 \%$ of the CRNA workforce (2015), which the US Bureau of labor Statistics [BLS] estimates to be approximately 39,410 domestically employed (2015).

Despite this gain in gender diversity, nursing overall has also seen evidence that significant and persistent difficulty exists for male nurses with regard to the relative proportion of disciplinary action taken against them by state Boards of Nursing throughout the country (Kenward, 2009; Lewis, Snodgrass, \& Larltin, 1990; Zhong, McCarthy, \& Alexander, 2016). Disciplinary action in many instances involves surrender or revocation of licensure and by extension, termination of membership in the profession. According to the literature, immediate surrender or revocation of license and subsequent loss of licensure is more common than any other single outcome of board discipline (Evangelista \& Sims-Giddens, 2008; Hudson \& Droppers, 2011; Kenward, 2009). This trend therefore represents a potentially negative impact on the gender diversity of nursing and healthcare systems. 
Gender disparities within the nurse anesthesia profession specifically, should they exist, may represent a negative impact on diversity, retention, and development of this nursing specialty. Conversely, if no disparities are observed, then further research may be warranted to see if a correlation exists between discipline practices in this specialty and the near gender balance unique to it within nursing. The presence or absence of gender disparities as evidenced through disciplinary actions related to CRNAs may inform the larger profession of nursing as a whole concerning issues of diversity management related to this and other minority groups.

Nurse anesthesia as a specialty is unique in part due to the remarkably high proportion of males involved in its practice (AANA, 2015). Little significant data related to the discipline and censure of CRNAs currently exists. The purpose of this study is to describe formal licensure discipline against CRNAs practicing in New England during a 33-year period (1983-2017). The intent is to evaluate the demographic profile, including possible gender stratifications, should they emerge, and see how these characteristics mirror or differ from those of nursing in general.

Next, the review of the literature will be presented. 


\section{Literature Review}

The review of literature was conducted using the following online academic research portals: CINAHL; PubMED; EBSCOhost; PsycINFO; and Google Scholar. A large number of terms were used initially before being refined to phrases comprising the following keywords: Nurs*, Anesthe*, CRNA, Disciplin*, Gender, Male, Substance, Abuse, \& Addiction. The wild card character (*) was used effectively to capture variation of words such as Nurse versus Nurses, and Nursing. Results were filtered initially to allow only peer reviewed articles and professional journals. The resulting works were then subject to high level manual review primarily limited to abstracts to eliminate opinion pieces, editorials and other non-research material. Further review excluded additional studies based on relevance. For example, studies with a primary focus on exploring methods for rehabilitation of anesthesia professionals post licensure discipline were disqualified due to being outside the explicit scope of review. After these refinements, remaining articles were reviewed in depth to assess their quality, inform the design of this research, and provide additional sources gleaned via references, which were likewise reviewed.

\section{Overview}

The vast majority of the studies found were primarily retrospective cohort studies conducted at the national and individual state levels. Within these studies, the broad scope of disciplinary action as handed down by BONs the nation over, are made clear, as are the common violations of standards and laws associated with such discipline. In addition, though the commonly known themes of medication errors and substance abuse can be seen in this body of literature, there also exists a spectrum of infractions that 
include failing to obtain CEUs, sexual misconduct, fraud, incompetence, or felonies unrelated to practice.

\section{State Level Studies}

Two such state-level studies were conducted by Chappell et al. (1999) based in Kentucky and Powers, Maurer, and Wey (2002) based in South Dakota. Chappell et al. (1999) utilized the entire database of the Kentucky Board of Nursing (KBN) $(n=92,461)$, covering a period of six years between 1989 and 1995. During this period, females represented $85.2 \%(n=83,610)$ of the nursing pool, but only $2.6 \%(n=2,179)$ of the female nursing pool were disciplined. Conversely, male nurses in Kentucky represented only $14.8 \%(n=4,295)$ of the nursing pool, yet $8.8 \%(n=377)$ of disciplined nurses, a rate over three times that of female RN's. APRNs were included among the total nursing pool used for this study, but were not differentiated in any way. Powers et al. (2002) analyzed the entire South Dakota Board of Nursing $(\mathrm{SBN})$ database $(n=80,037)$ for the years of 1998 and 1999. During this period, $0.51 \%$ of nurses were disciplined $(n=339)$. Female nurses made up $94.3 \%(n=75,507)$ of the nursing pool and $82.5 \%(n=280)$ of disciplined nurses. Male nurses represented $5.7 \%(n=4,530)$ of the nursing pool and $17.4 \%(n=59)$ of disciplined nurses for a discipline rate over three and a half times that of female RNs. APRNs were not included in the analysis of discipline for this study.

Another study conducted by Evangelista \& Sims-Giddens (2008) utilized public discipline records published quarterly in Missouri over a period of 48 months between 2000-2004. These records were systematically coded for gender, infraction type, disciplinary action type, and other variables before being analyzed. Evangelista and 
Sims-Giddens found that among disciplined nurses practicing in Missouri ( $\mathrm{n}=627)$, males, in addition to having disproportionate discipline ratio of $18.9 \%(\mathrm{n} \approx 118)$ versus a $7.5 \%$ base population share, also "received more severe discipline than female nurses, regardless of number of infractions or license level, with higher percentages of suspension and revocation" (p.511). Licensure suspension of males was $7.6 \%(\mathrm{n} \approx 47)$, a number only slightly higher than the total percent of males (7.5\%) found in the nursing pool. Female suspensions were $5.1 \%(\mathrm{n} \approx 32)$ versus women being $92.5 \%$ of the nursing pool. Likewise, male licensure revocations were $18.5 \%(\mathrm{n} \approx 115)$ while license revocation was about half that, at $9.6 \%(\mathrm{n} \approx 60)$ of female disciplinary actions. The rates of license surrender were also noteworthy with males voluntarily surrendering licensure at $22.3 \%$ $(n=23)$ versus female rates of $77.7 \%(n=80)$. Also of note, this study reported that substance abuse ranked as the majority infraction at $41.3 \%(n=259)$ of cases. Regarding APRNs, Evangelista et al. did not consider them separately from the general body of nursing except in the breakdown of infraction types in which APRNs were disciplined for prescribing scheduled drugs, representing $1.8 \%(\mathrm{n}=11)$ of infractions (2008).

Similarly, researchers Hudson and Droppers (2011), utilizing the Nursys database, found that of all RNs disciplined in Oregon from 1996 to 2008 (n=720), most disciplinary action fe 11 along the demographic lines of gender as well. While males were $10 \%$ of the nursing pool, they saw a disproportionate amount $(19 \%, \mathrm{n}=137)$ of disciplinary actions, at a rate of 1.9. In contrast, female nurses, which represented $90 \%$ of the nursing pool, received $81 \%(\mathrm{n}=583)$ of disciplinary actions, a rate of 0.9 , less than half that of males (Hudson \& Droppers, 2011). Hudson and Droppers also cited substance abuse related infractions as the most heavily represented at $31.4 \%(\mathrm{n}=226)$. Concerning APRNs, 
Hudson and Droppers did not distinguish between specialties, but noted that APRNs comprised $2.5 \%(n=18)$ of disciplined nurses during the study period versus being $5 \%$ $(n=2140)$ of the total nursing pool (2011). Additionally, APRNs were most often disciplined for failure to maintain records and were more likely to surrender their licenses for substance abuse violations (2011).

Another state level study by University of California, San Francisco researchers Waneka, Spetz, and Keane (2011) used Nursys data to investigate the characteristics of nurses placed on probation in California between the years of 2004 and $2005(n=282)$. This was completed in order to help the California Board of Registered Nursing identify salient attributes of those at risk for being placed on probation and analyze probation outcomes. Waneka et al. concluded that the average nurse on probation during the study period was younger (44 yrs), less experienced (11.5 yrs), male, associate's degree educated, and worked for a nursing registry. Men comprised $25.9 \%(n=73)$ of RNs on probation, but only $9.1 \%$ of all California RNs. Conversely, women held $90.9 \%$ of the total RN pool and $74.1 \%(n=209)$ of the probation sample. The offenses most commonly seen involved drug or criminal misconduct $(67 \%, \mathrm{n}=189)$ and the majority of nurses who did not complete probation $(66 \% \mathrm{n}=84)$ lost their license via revocation or surrender. Waneka et al. also noted APRNs on probation during the study period with NPs $2.8 \%$ $(n=8)$, CRNAs $0.7 \%(n=2)$, CNMs 0.4\% $(n=1)$, and CNSs $0 \%(n=0)(2011)$. None of these APRN specialties were overrepresented with respect to their percentage of the total nursing pool during the study period (Waneka et al.). 


\section{National Level Studies}

At the national level, two noteworthy and comprehensive studies are those of Lewis et al. (1990) and Kenward (2009). Each study descriptively analyzed large data sets provided by the National Council of State Boards of Nursing (NCSBN) and further illustrated the trend of males being over represented in discipline demographics. In addition, substance abuse and drug-use related behavior violations consistently ranked as the most prevalent infraction category in both of these studies, which demonstrates another long standing trend.

Lewis et al. (1990) took the unique approach of illustrating these trends at the state level. They focused on Massachusetts $(n=442)$ between 1985 and 1988 and compared this data against a randomly selected national data sample $(n=3193)$ obtained from the NCSBN during the same years (1990). Lewis et al. found that at both the state of Massachusetts and national levels, males represented 3\% of the nursing force, yet 19\% $(n=82)$ of state and $18 \%(n \approx 574)$ of national disciplinary hearings involved men. This represented a rate of over six times that of their female counterparts.

Kenward's work (2009) in addition to being the more contemporary of the two studies by almost 20 years, examined the entire NCSBN national discipline data aggregate $(n=107,688)$ spanning the years of 1996 to 2006 in great detail. The author considered not only demographics, but also violation types in relation to the actions taken by the state BONs. Kenward noted that in addition to being overrepresented in the gross discipline numbers $(6 \%$ of nurses were male, representing $17 \%(\mathrm{n}=8,157)$ of disciplinary actions), male nurses were markedly overrepresented in drug-related violations (19\%; 
$\mathrm{n} \approx 3,683)$, with revocation or surrender of license resulting in nearly $15 \%(\mathrm{n}=32,386)$ of drug violation cases (Kenward).

A more recent study by researchers Zhong el al. (2016) reviewed NCSBN disciplinary data between 2012 and 2013 to identify trends among the approximately $10 \%(n=4,819)$ of nurses and nurse applicants disciplined due to receiving a criminal conviction. State BONs prosecute these actions in the interest of public safety, to prevent newly convicted individuals from having access to the vulnerable populations served by the nursing profession. Zhong et al. discovered that during their study period, "male nurses and licensed practical nurse/vocational nurses were overrepresented as compared to their proportion in the national nursing workforce" (p. 27), males being $8 \%$ of the workforce, but $23 \%(n=759)$ of the sample. The most common convictions resulting in BON discipline were driving under the influence $(29 \% ; n=1,990)$, violation of the Controlled Substances Act $(17 \% ; n=1,187)$ and theft $(16 \% ; n=1082)$. This study is particularly interesting due to the continued element of gender stratification in discipline despite a large, national sample size with narrowed criteria for inclusion.

\section{Advanced Practice Registered Nurse (APRN) Specific Studies}

The literature revealed fewer studies that specifically examined APRNs, and CRNAs, in particular. This is likely due to the fact that APRNs were not differentiated in earlier data tracking methods and currently, even in many states where APRN data is tracked, there is no distinction made between specialties. Even in the more recent studies cited above, where APRNs were considered as a category unto themselves, specialties have not been considered separately, for example as CRNAs, in most cases. Though 
Kenward's (2009) national data review, discussed previously, pointed out that APRNs accounted for only $1 \%(\mathrm{n}=1052)$ of disciplinary actions carried out by BONs, it did not provide any insight as to which specialties were represented, what violation types were common among each or what actions were typically taken (2009).

Only three studies with information specific to CRNAs were located. Waneka et al. (2011), which was previously reviewed, did include a small section on APRNs. They noted that the ratio of APRNs on probation was less than the average for nursing in general, with APRNs being 3.9\% ( $\mathrm{n}=11)$ of the probation sample vs. $12 \%$ of the total nursing population. The only specific mention of CRNAs was in a data table that further broke down recipients of probation for the study period by specialty: NPs $2.8 \%(\mathrm{n}=8)$, CRNAs $0.7 \%(\mathrm{n}=2)$, and CNMs $0.4 \%(\mathrm{n}=1)$, with no further information, demographic or otherwise, concerning the APRNs on probation.

The second study by Hester, Green, Thomas, and Benton (2011) focused explicitly on nurses with multiple disciplinary actions related to practice errors in Texas. Data were retrieved directly from the Texas BON discipline database by the IT manager based on license number, de-identified, a coding system implemented, then manually reviewed by the researchers. This study, though limited by a small sample size ( $\mathrm{n}=59)$ and strict inclusion criteria, reiterated that even in a highly refined sample, men were over represented proportionally, comprising $23.7 \%(\mathrm{n}=14)$ of the sample and only $9.8 \%$ of RNs in Texas. Advance practice nurses as a group represented $10.2 \%(n=6)$ of recidivists with CRNAs at $6.8 \%(n=4)$, NPs at $3.4 \%(n=2)$, with no other correlates or conclusions related to either specialty (Hester et al.). 
The third study, conducted by Hudspeth (2007), used a voluntary response survey method and was aimed at describing the proportion of BON disciplinary actions relative to the overall APRN population, which was defined as CRNAs, NPs, CNMs, and Clinical Nurse Specialists (CNSs). Hudspeth collected no demographic information from the respondent BONs in his survey, thus adds nothing related to gender stratification, but concluded that between 2003 and 2004, the incidence of APRN discipline was minimal nationwide at $0.54 \%$ ( $\mathrm{n}=688$ ) of BON disciplinary actions (Hudspeth, 2007). This figure, despite being notably lower than Kenward's later findings of $1 \%$ (2009), does mirror the generally low ratio of APRN to general nursing discipline nationwide. Hudspeth described APRN infractions in terms of categories: patient abuse and safety issues at $30 \%$ $(\mathrm{n}=210)$, unprofessional conduct at $28 \%(\mathrm{n}=194)$, chemical impairment at $21.5 \%$ $(\mathrm{n}=147)$, and exceeding the scope of practice at $20 \%(\mathrm{n}=137)$, leaving $0.5 \%$ unaccounted for (2007). Though it was not mentioned by Hudspeth in text, the data table included with the publication addressed each APRN specialty in the sample individually. Nurse practitioners made up 69\% ( $\mathrm{n}=86,940)$, CRNAs 19\% ( $\mathrm{n}=23,944)$, CNSs $7.4 \%(\mathrm{n}=9,257)$, and CNMs at $4.6 \%(n=5,741)$ of the sample populations respectively (2007). The data in this table also indicated which portions of the infraction sample $(n=688)$ were derived from each specialty. Of note, NPs were over represented in the infraction category of "patient abuse and safety issues" at $94 \%(\mathrm{n}=199 / \mathrm{n}=210)$ versus being $69 \%$ of the sample for an increased infraction rate of 1.3 times the other specialties. Likewise, CRNAs embodied a distinctly higher proportion of APRNs disciplined for "chemical impairment" at $42.8 \%(n=63 / n=147)$ while representing only $19 \%$ of the total sample for an increased infraction rate of 2.25 times the other specialties (Hudspeth). 


\section{Studies involving Nurse Anesthesia}

The APRN specific studies considered above, though not exclusive or specific to CRNAs, foreshadow important implications of the twin facts that the nurse anesthesia specialty endures unusually high rates of substance abuse among healthcare professions (Bell, McDonough, Ellison, \& Fitzhugh, 1999; Hamza \& Monroe, 2011; Wright et al., 2012) and that males find their largest numbers in this specialty (USCB, 2013; AANA, 2015). The US Bureau of Labor Statistics characterizes the primary workspace of nurse anesthetists as physician offices, hospitals, and outpatient care centers and places them geographically in sync with the general population spread of the US (2015). This type of diversity implies a wide variety of responsibilities, pay and inherent stress.

Researchers Bell et al. (1999) conducted the first comprehensive nationwide survey of substance abuse targeting the CRNA population $(n=2,500)$ through a voluntary survey analysis with a $68.4 \%$ return rate $(n=1,709)$. The authors concluded that roughly $10 \%(\mathrm{n}=167)$ of respondents had previously, recently, or were currently engaged in substance misuse. The demographic data showed that misusers were more likely to be males $(62 \% ; n=105)$, between the ages of 31 and $45(n=135)$, and living in urban areas $(n=123)$ of the Midwest and Southeastern US $(n=99)$. The most commonly abused substances were identified, with the top three being benzodiazepines, nitrous oxide, and opioids, before concluding that with an incidence rate of one in ten, this problem warrants more research and an active prevention effort (1999).

Follow-up data compiled by Bell in 2006 and published by others, reaffirmed these findings and showed an increase in opioid abuse (Hamza \& Monroe, 2011; Wright 
et al., 2012). In their article Opioid Abuse Among Nurse Anesthetists and

Anesthesiologists, Wright et al. (2012) identified occupational risk factors for anesthesia providers as stress related to high patient acuity leading to poor coping, access to freely available and highly addictive substances, attitudes and perceptions of knowing how to administer and properly control the substances in question leading to a false sense of immunity from the dangers of addiction, and lastly the potential for inadvertent exposure to aerosolized substances over time. Despite such data related to the profession of anesthesia and the high incidence of substance abuse-related infractions seen in the sphere of BON disciplinary actions, there are currently no available studies specifically examining disciplinary actions related to CRNAs.

\section{Summary}

The studies reviewed share essentially identical methods, namely the retrieval of data from publicly managed databases, and thus have similar if not identical limitations. These limitations are best summed up by Kenward (2009) who described those of his own study as "inaccurate and incomplete data" (p. 19) due to data entry errors on the part of BONs personnel charged with recording them, which subsequently trickled down to populate Nursys. In the APRN specific literature, Kenward's study encompassed only 44 of the available 51 BONs and Hudspeth's work did not include two New England states, which is a gap that will be covered by the sample population of this study. The studies related to substance abuse, such as those performed by Bell et al. (1999), suffer from limitations inherent to self-reported survey tools, which rely on the memory of the respondent for accuracy and willingness of those sampled to participate, thus they require large sample sizes to off-set these issues and promote generalizability. 
The recent literature supported the historical trend that male nurses, despite being a minority population within nursing overall, incur an unusually high proportion of the disciplinary actions taken by state Boards of Nursing. Furthermore, there is a deficit of APRN specific data related to this topic and almost none directly related the CRNAs. Of note, is the fact that different BONs impose different actions for the same violation, and any single BON may impose different actions for the same violation within its own jurisdiction. When considering these variations in the delivery of discipline, one can easily question the potential for inadvertent bias, especially with regard to the consistent overrepresentation of males among those disciplined nationwide. To date, only one study has attempted to explore the phenomenon.

A mixed methods study by researchers Smiley and McCarthy (2016) used a voluntary response survey and secondary analysis of discipline data to investigate the possibility of bias, either in reporting or delivery of discipline, that may account for the overrepresentation of males in this way. This well thought out study detected no substantial bias in either area, but admitted to limitations of sample size and lack of validation of the survey tool used (Smiley \& McCarthy, p. 39, 2016). In addition, the data set was limited to nurses with criminal convictions and a letter of purpose was sent with each survey, both of which may have altered the outcome. Despite the ambition and excellent design of Smiley and McCarthy's efforts to better understand the root of this phenomenon, much more research is needed to draw a strong conclusion or rule out bias as a contributor. Furthermore, speculation of the root causes surrounding this phenomenon are beyond the scope of this study, which aims simply to broaden the scope of discipline research to include the population of Nurse Anesthesia. 
Next, the theoretical framework that guided this study design will be described. 


\section{Theoretical Framework}

Trends seen in the discipline of CRNAs in New England (NE) may be relevant locally to administrators, managers, the respective BONs or to CRNAs themselves as a professional body. In a broader scope, the results may be insightful to the National Council of State Boards of Nursing (NCSBN), the AANA, or federal bodies such as the Bureau of Health Professions (BHPr). The common theme can be classified as either organizations or individuals with key organizational responsibilities. Based on this, the framework chosen to guide this study was the Social-Ecological Framework of Workforce Diversity (Bond \& Haynes, 2014).

\section{Introduction: Workforce Diversity}

Within the field of organizational theory lies the subset of concepts known as workforce diversity, pioneered by researcher R. Roosevelt Thomas, in which the impact of an increasingly diverse workforce in the United States (US) is described and explored (1990). Roosevelt proposed that organizational goals of avoiding negative repercussions of affirmative action type legislation should be superseded by perceived advantages of a diverse workforce (1990). Page (2007) agreed with these observed benefits and set out to support workforce diversity through empirical research focused on problem solving groups. Page's work has consistently provided support to his claims that highly diverse groups are superior at problem solving and predictive analysis (2007). Additionally, there exist a number of relevant studies linking diversity in the healthcare workforce to public health outcomes (HHS, 2006; 2011). 


\section{Framework}

The social-ecological framework of workplace diversity as proposed by researchers Bond \& Haynes (2014) aims to bridge the gaps between apparently conflicting concepts of workplace diversity in order to avoid or diminish intergroup conflict, while maximizing the advantages of diversity. Their framework proposed four main tenants:

(1) principle of multiple levels — organizational issues are best understood as nested within multiple levels of context, (2) principle of interdependence - any event, interaction, or intervention — observable or subtle — within an organization can have reverberating effects throughout the entire system, (3) principle of phenomenology-based impact—people's experiences of events shape reactions and the impact of practices as perceived by varied groups shapes organizational consequences, and (4) principle of person-environment adaptation-people and groups within organizations are continually adapting to not only one another but also to organizational resources and requirements (Bond \& Haynes, 2014, p. 184)

This framework provides direction for this descriptive study. Principle 1 (multiple levels) relates to the complexities of context surrounding the unique healthcare space filled by male CRNAs. Male CRNAs are a minority group within the larger and historically marginalized groups, mainly women, that comprise the nursing profession, yet are nearly equally represented in nurse anesthesia. Added to this is the difficult negotiation of mid-level practitioner status as assigned by physicians and many administrators to APRNs versus the advanced level status assigned by nursing. Principles 
2 (interdependence), 3 (phenomenology-based impact), and 4 (person-environment adaptation) are directly applicable to disciplinary actions and their influence on the diversity of the nursing workforce.

Next, the study methods will be presented. 


\section{Method}

\section{Purpose}

The purpose of this study was to describe formal licensure discipline against CRNAs practicing in select states during a 33-year period (1983-2017).

\section{Research questions}

The study sought to answer two questions which emerged:

1. Does the trend of gender-stratified discipline hold true for CRNAs in the states examined?

2. What patterns of infraction, discipline type and demographics are evident within this population?

\section{Design}

This descriptive study was classified as a retrospective cohort study involving secondary data analysis of public records information.

\section{Procedures}

This proposal was submitted to the RIC IRB for review prior to requesting permission from the individual states to use their data despite such data being public domain. Permission was granted by all BONs that were successfully contacted. Next, data were retrieved via the database tools accessible on the government websites provided by each state department of health and/or BON. List data, which was fully identified, detailing which licenses had been disciplined, was downloaded using these tools and then cross-referenced against the publicly available Nursys database offered by 
the National Council of State Boards of Nursing (NCSBN). The Nursys database provides specifics of each infraction and disciplinary action related to each license. The NCSBN collects disciplinary data from its member boards nationwide for inclusion into the Nursys database. Nursys was initially designed to facilitate information sharing between state boards regarding licensure and discipline matters for public safety. However, it also acts as a central data storage site from which retrospective analysis can be conducted. Data retrieved for this study encompassed a non-specified geographic region, for the period of January 1983 to July 2017. Identifying data such as name and license number included in the discipline dataset were removed and replaced with a unique identifier, despite such identifying data being available as a matter of public record.

\section{Sample}

The sample consisted of nurse anesthetists in a non-specified geographic area who received BON discipline during the period of January 1983 to July 2017.

\section{Measurement}

Relevant data fields included gender, violation type, violation date, board actions, license type, license status, and location of practice. Violations are named and typed differently by different BONs, but follow common themes. The label Diversion of Narcotics may be used by one BON, while Diversion of Controlled Substances may be used by another. For the purpose of this study violations were sorted into the following infraction type categories: substance abuse; unprofessional conduct; unsafe practice; documentation; noncompliance; and licensure issues. Information regarding name and 
license number were stripped from the data once it had been used to retrieve needed disciplinary information from online database tools or used to establish gender in cases where such data were not specifically delineated. The records for each state were retrieved and processed individually and then compiled and analyzed as an aggregate.

\section{Data analysis and storage}

In many cases the number of violations and disciplinary action entries per individual license did not exist in a 1:1 ratio. This variation generally stemmed from one of three occurrences. Recidivism, cases in which an individual was charged on multiple separate occasions, often for repeat offenses, was one reason for these altered ratios. Other reasons included cases in which multiple disciplinary actions result from a single violation or the reverse instance of multiple infractions resulting in a single board action. For the purposes of this study, BON licensure actions which were not disciplinary were not considered. Examples of such actions include reinstatement of license or relief from probation.

In cases where recidivism was a factor, each new infraction resulting in

disciplinary action was counted as a separate disciplinary event for analysis. Conversely, incidents in which multiple actions result from a single infraction were considered as only a single action with the most severe action listed. For example, if an infraction resulted in a monetary fine and suspension of licensure, the sanction was listed as suspension. In cases where multiple infractions were cited, but a single board action was taken, the official public record of the incident and proceedings was consulted to determine the most prominent aspect of the infraction so that it could be categorized. 
Since no statistical relationships or correlates were hypothesized in this study, the lack of a 1:1 ratio between license and disciplinary actions required no special analytical consideration. Useful ratios and trends are still evident via descriptive statistics. Analyses was conducted on all variables included in the aggregated master datasets in order to maximize the identification of any potentially insightful trends. Comparison of demographics, violation types and board actions was conducted using Windows Excel 2016 with academic stats package. All data exists in digital format and is stored electronically, de-identified, on a Unix based computer system using 128bit file encryption and unique passkeys. 


\section{Results}

\section{Aggregate Sample}

Data from four states in the study area provided a total sample of 4,401 CRNAs during the period of 1983-2017. Figure 1 illustrates the breakdown of sample per state with the state names removed as an additional method of protecting the individuals whose licensure information comprised this study. State 1 ,

2, 3, and 4 contributed $8.04 \%(n=354)$,

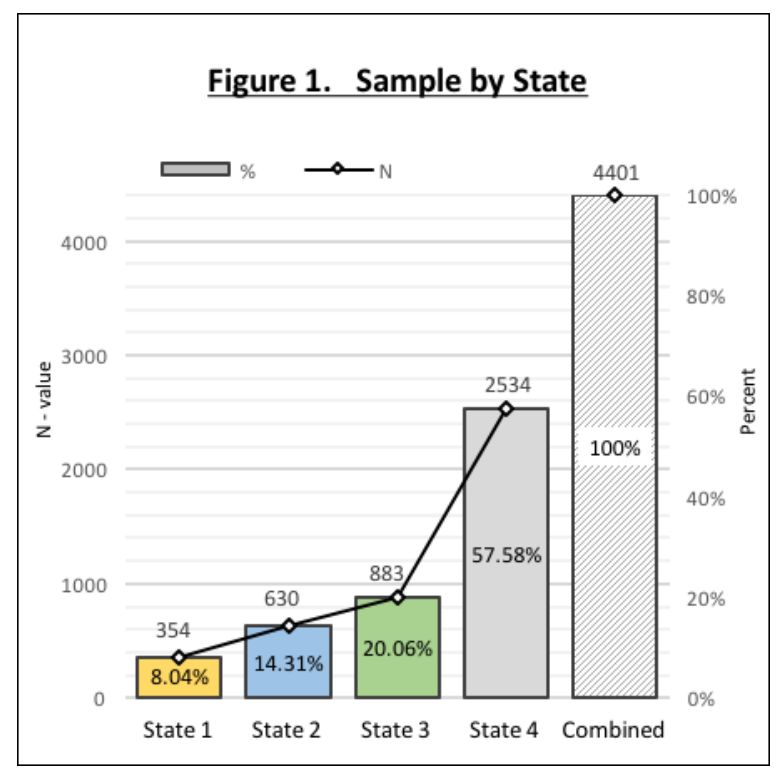
$14.31 \%(\mathrm{n}=630), 20.06 \%(\mathrm{n}=883)$, and $57.58 \%(\mathrm{n}=2534)$ respectively. These percentages correlate approximately with the respective state populations, lending strength to accuracy of the sample as overall representation (USCB, 2010).

\section{Gender}

The majority of the total sample, $62.64 \%(n=2757)$ were female, with the remaining $37.36 \%(n=1644)$ being male (Figure 2). These numbers are consistent with those provided by the AANA, listing women as $60 \%$ and men as $40 \%$ of the

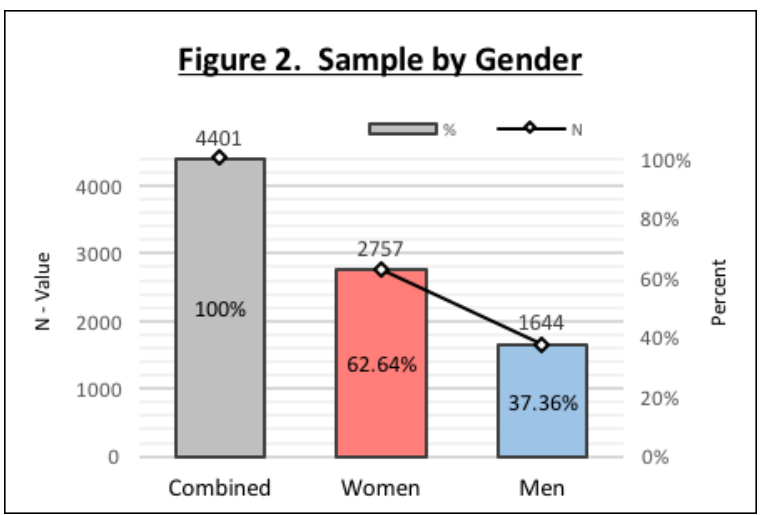
national CRNA workforce (2015). 


\section{Number Disciplined}

Of the sample group, only $1.20 \%(n=53)$ were sanctioned, with the remaining $98.80 \%(n=4348)$ unsanctioned (Figure 3). The number of infractions by state can be seen in Figure 4 with states 1, 2, 3, and 4 being 22.64\% ( $n=12), 13.21 \%(n=7), 22.64 \%(n=12)$, $41.51 \%(n=22)$ respectively. States 2 and 3 had infraction rates that were proportional to their share of the total sample within 1-2\%. State 1 was over-represented in the disciplinary sample with infraction rates 2.75 times higher than those of the other states. Conversely, state 4 was under-represented, with an infraction rate approximately $16 \%$ lower than the other sample states.

Figure 3. Discipline by Percent

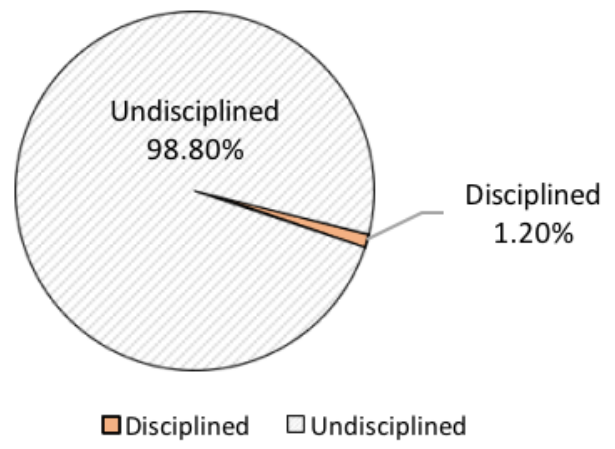

Figure 4. Disc. by State

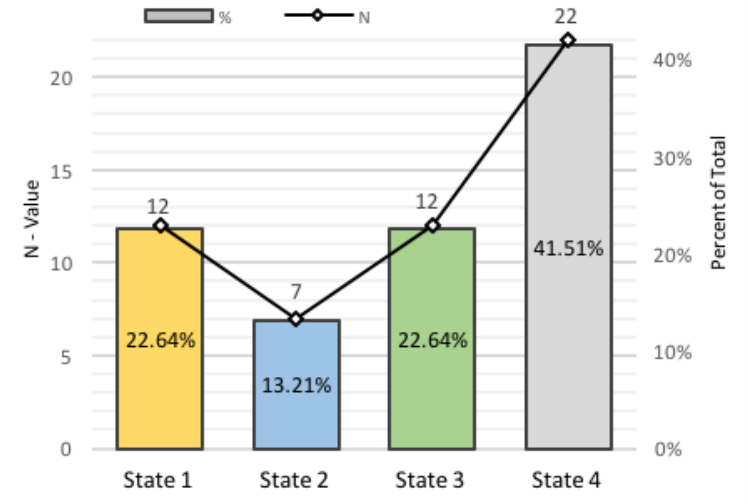

\section{Gender Discipline}

Of the total infractions, $50.94 \%$ $(\mathrm{n}=27)$ were women, with the remaining $49.06 \%(\mathrm{n}=26)$ being men (Figure 5). Males are somewhat over-represented, at $49 \%$ of discipline, while being $37 \%$ of the sample, a difference of 0.6 times.

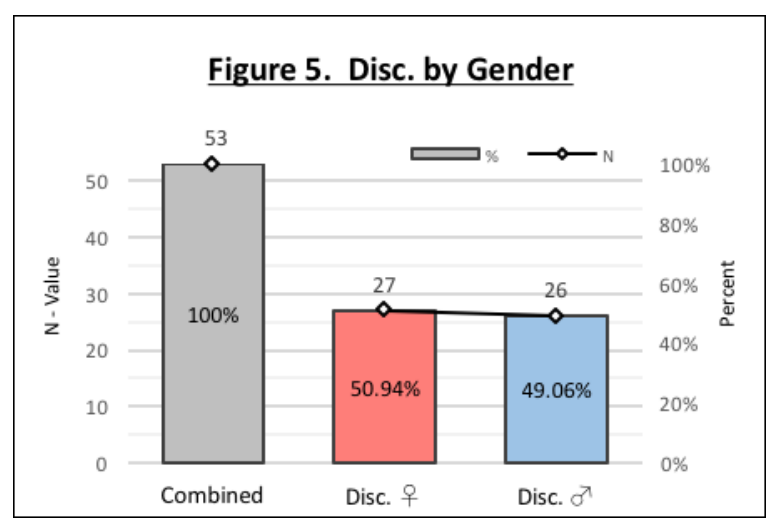




\section{Infractions}

Six main infraction types emerged within the sample data as depicted in Figure 6. Unsafe practice represented $13.21 \%(n=7)$, substance abuse $66.04 \%(n=35)$, unprofessional conduct $9.43 \%(n=5)$, non-compliance $5.66 \%(n=3)$, documentation issues $3.77 \%(n=2)$ and licensing issues $1.89 \%(\mathrm{n}=1)$. Substance abuse violations were a notable majority at $66 \%$, with all other infraction types combined totaling just under 34\% (Figure 7).

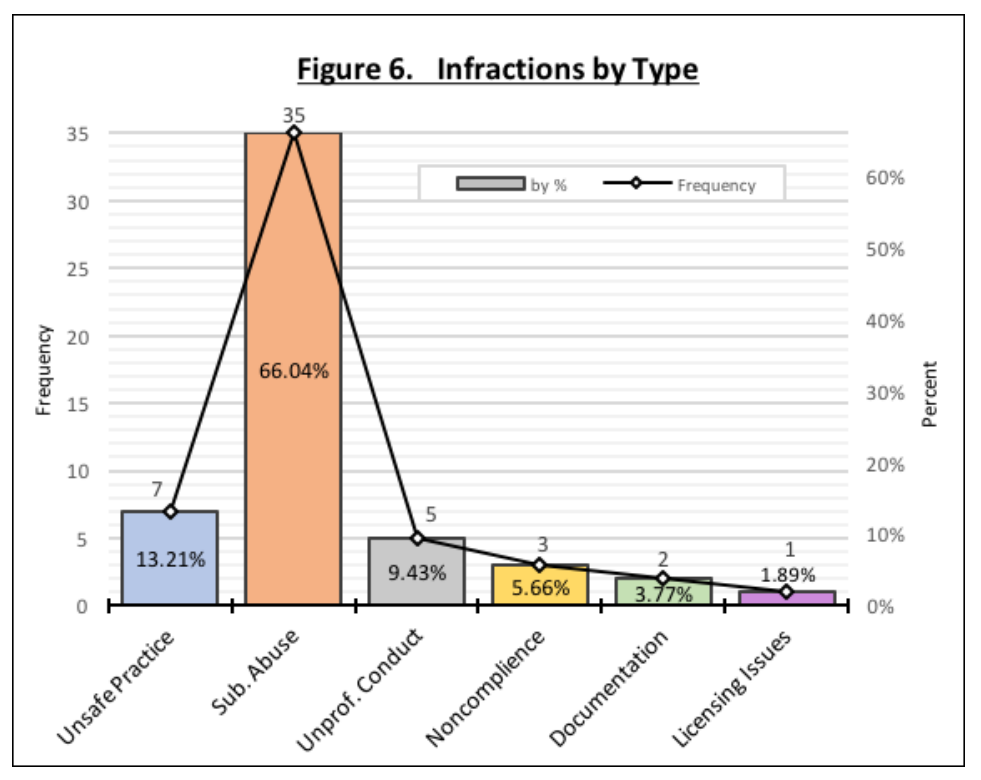

Figure 7. Sub. Abuse Disc.

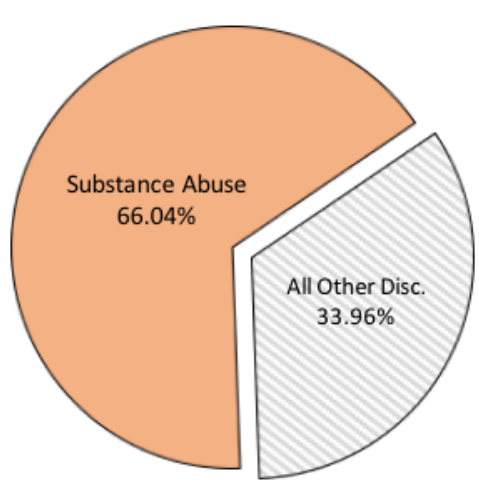

$\square$ Substance Abuse $\square$ All Other Disc.

\section{Infractions by Gender}

In considering violations by gender, some noteworthy differences were seen as illustrated in Figure 8 on the next page. Though both genders saw their largest infraction percentages in substance abuse, the rates for women, at $43 \%(n=23)$, nearly doubled those of men at $22 \%(n=12)$. Conversely, males had higher infraction numbers in every other category with the exception of documentation errors which were split equally. For males, after substance abuse violations, the next highest frequency infraction type was 


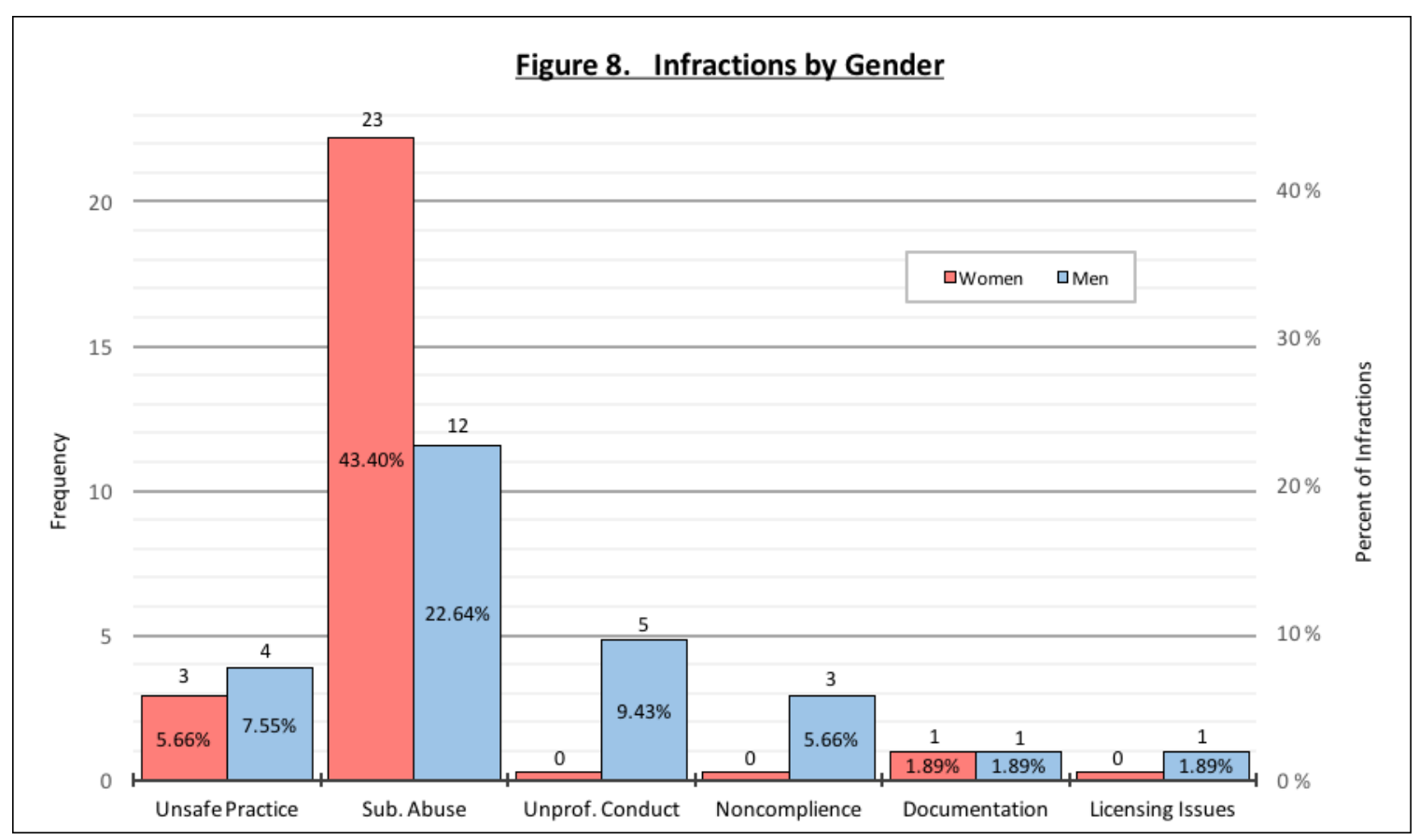

unprofessional conduct at $9 \%(n=5)$, followed by unsafe practice at $7 \%(n=4)$, followed by noncompliance at $5 \%(n=3)$, and finally licensing issues at $1.89 \%(n=1)$. For women, the second highest frequency infraction type after substance abuse was unsafe practice at $5 \%(n=3)$, followed by documentation issues at $1.89 \%(n=1)$. Three categories, unprofessional conduct, noncompliance and licensing issues, were devoid of female violators.

\section{Infractions Over Time}

As illustrated in Figure 9 on the next page, incidents were lower early in the study period, oscillating between $0 \%$ and approximately $2 \%$ during the early ' 80 s to the mid ' 90 s. The number of infractions then climbed in the late ' 90 s and early ' 00 s to approximately $5 \%$. In the mid ' 00 s there is a drop to around $3 \%$, followed by an upward trend to $9-11 \%$ between 2007 and 2014, then another decline to between 4-7\% late in the study period towards 2017. The number of infractions receiving board action over time were variable, 


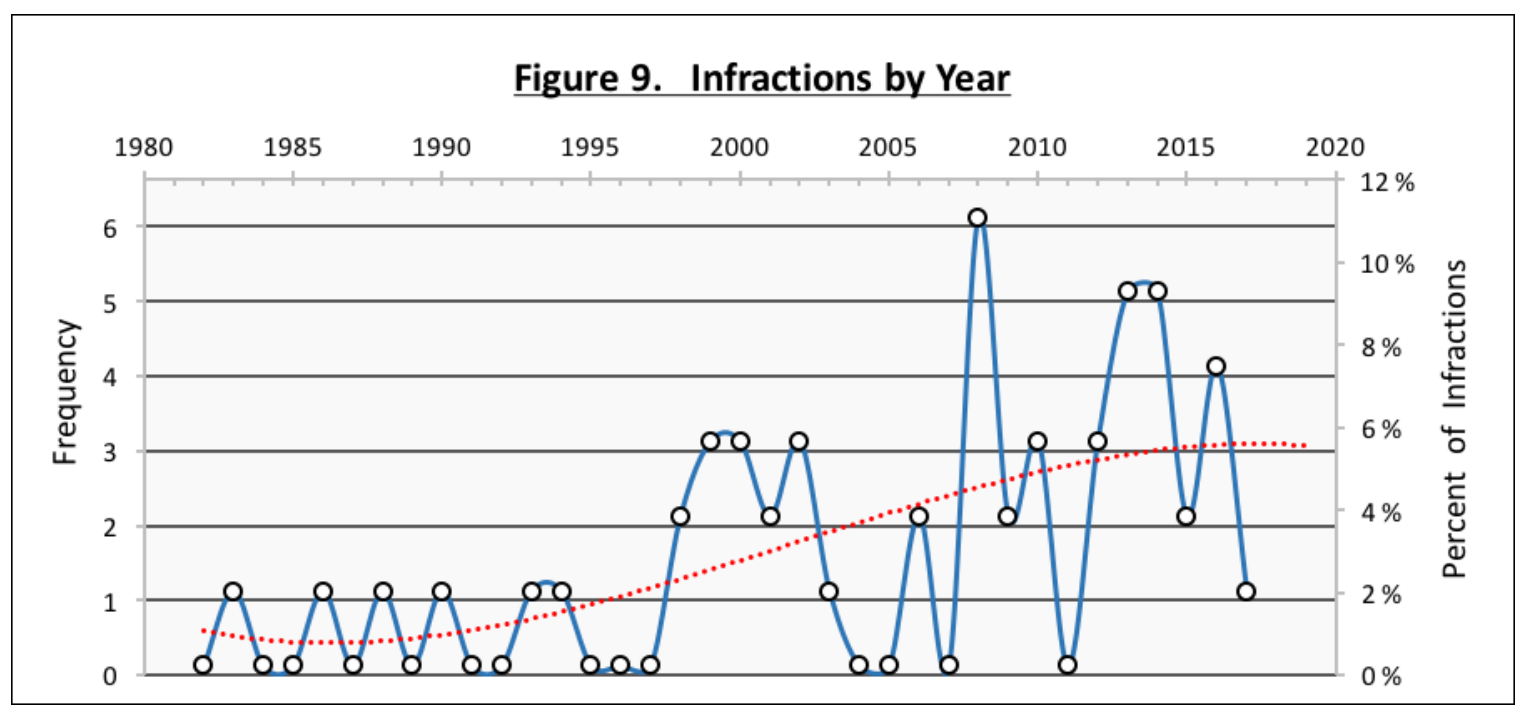

changing significantly from year to year. However, when graphed via scatter plot, a visible pattern emerges showing an overall trend of increasing infractions over time (Figure 9).

\section{Board Sanctions}

Disciplinary actions issued by BONs within the study area also fell into six main categories as illustrated in Figure 10. Surrender of licensure was the most prevalent sanction at $33.96 \% \quad(\mathrm{n}=18)$, followed by probation at $28.30 \%(n=15)$, reprimands totaled $18.87 \% \quad(\mathrm{n}=10)$, revocation of license $9.43 \% \quad(n=5)$, suspension of license $7.55 \%(n=4)$, and lastly fines being the least frequent

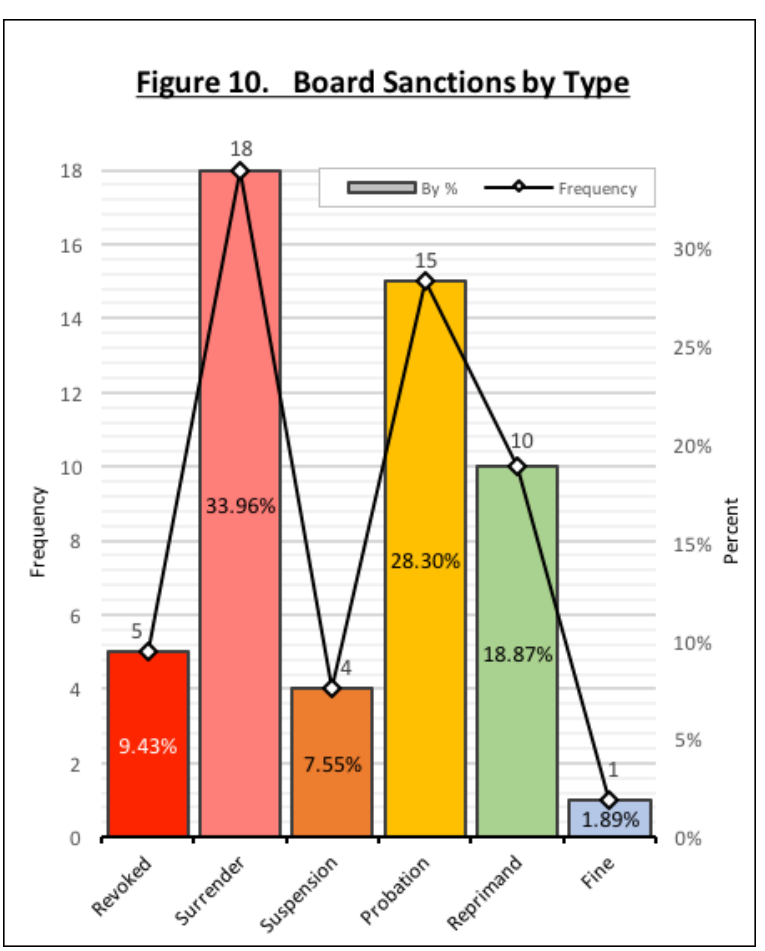
solitary board action at $1.89 \%(n=1)$. A 
notable detail when considering severity of BON actions is that sanctions resulting in loss of licensure together totaled approximately $51 \%(\mathrm{n}=27)$ with all other discipline combined, totaling 49\% $(\mathrm{n}=26)$ of actions as illustrated in Figure 11.

Next, summary and conclusions will be presented.

\section{Figure 11. Loss of Licensure}

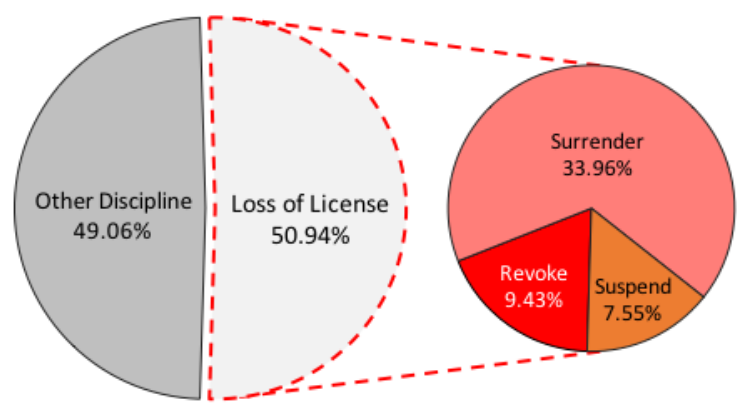

$\square$ Other Discipline $\square$ Revoke $\square$ Surrender $\square$ Suspend 


\section{Summary and Conclusions}

Great diversity exists in the US population, therefore the HHS has called for increased diversity in healthcare professionals as a means of improving public health outcomes (HHS, 2006; 2011). Nursing professionals, who are in direct contact with this diverse patient population (Benner et al., 2006; HHS, 2006; Thomas, 2010), are the most numerous sector of healthcare (NCHWA, 2015) and therefore could benefit the public through diversity within its ranks. Males are consistently a minority group within the nursing profession and are disproportionately disciplined (Kenward, 2009; Lewis, Snodgrass, \& Larltin, 1990; Zhong, McCarthy, \& Alexander, 2016). Board of Nursing discipline commonly results in loss of licensure; thus the disproportionate discipline of males may impact efforts to diversify the nursing sector of healthcare.

Within the anesthesia specialty of nursing, the ratio of males to females is more equal (AANA, 2015) and little data exists examining the characteristics of disciplined CRNAs. Thus the aim of this study was to compile data from existing sources for a secondary analysis in order to describe BON discipline among CRNAs in the study region.

This study analyzed CRNA disciplinary data reported by four BONs between the years of 1983 and 2017. When comparing this data to disciplinary data of the general RN population, many key points of interest emerge. The rate of CRNA sanction of $1.20 \%$ as reported in this study, though ostensibly low, is actually elevated as compared to Kenward's 2009 findings. Kenward reported the cumulative RN sanction between 1996 and 2006 at $1 \%$ and APRN sanctions at $0.34 \%$. Likewise, Huspeth's 2007 study found 
APRN discipline between 2003 and 2004 to be low at $0.54 \%$ and CRNA discipline based on his data was set at about $0.1 \%$. In comparison, the CRNA discipline rate of $1.20 \%$ in this author's study was $20 \%$ greater than that of the general RN population set forth by Kenward and 12 times greater than the CRNA discipline rate of Huspeth's report. However, Kenward's report did not provide any CRNA specific numbers to which a direct comparison could be made and Hudspeth's data was survey based. Thus, no strong comparisons of this type between CRNA discipline and that of general nursing can be made until a comprehensive national report of CRNA discipline is published.

Another significant finding of this study was though men were over- represented in disciplinary actions, the ratio was much less at only +0.6 times for each female sanction. This is a notable decrease compared to the studies cited previously, in which males of the general RN population were disciplined at rates over 2-3 times those of females. Along similar lines, the number of substance abuse related infractions committed by men were substantially lower $(-15 \%)$ than in the general nursing population, where men were consistently over-represented as well.

Regarding the number of infractions over time, the overall trend was upward with a notable increase starting in the late 1990s. Kenward (2009) showed the same general trend of increasing rates of infractions during similar time frames. This is most likely due to national level policy changes in reporting and record keeping implemented during this time, most notably, the deployment of the Nursys database in 1999. This application provided a standardized platform for reporting BON discipline and was effectively promoted by the NCSBN. 
In considering the nature of provider infractions, an overwhelming majority of violations fell into the substance abuse infraction category. The CRNAs in this study were six times more likely to commit an infraction related to substance abuse than any other single infraction type and two times more likely to do so than all other violation types combined. These results support findings of the numerous studies cited above and reinforce the high level of risk for substance abuse among CRNAs. However, though these findings support the general consensus of substance abuse as the greatest risk area for CRNAs, one countervailing point is the difference seen in the ratio of substance abuse violations to the overall sample. Substance abuse violators disciplined in this sample represent only $0.8 \%(n=35)$ of the total sample $(n=4401)$, which is far less than the $10 \%$ estimated by Bell's 1999 and 2006 data. One possible explanations for this is the recovery and rehabilitation program alternatives to discipline that are employed by many BONs. This is primarily due to the recognition of addiction as a disease state requiring treatment and secondarily as an effort to stem the loss of providers in today's environment of provider shortages. Another possible explanation is that the overall low incidence could be unique to the geographic area of the sample, but such speculations are beyond the scope of this study and would again require a larger, more inclusive national data set to confirm.

Data from four states in the study area were retrievable using available online BON database tools. The actual total number of licenses during the study period could not be determined due to limitations of these online tools. Some states allow the generation of lists containing both expired licenses and active licenses, while others only allow generation of lists containing active licenses for the periods in question. At the time 
of this study, two states in the study region did not offer online database tools for extraction of licensure or disciplinary action list data. For these reasons, the sample, though adequate, is not complete. Similarly, BON actions listed in this study are those related to discipline only. If an infraction was reported to the board and resulted in the respondent enrolling into a recovery or remediation program, then disciplinary action may have been avoided and the incident would not be included in this study. For this reason, the results do not encompass the totality of infractions or incidents that have occurred in the study area during the timeframe. Other limitations include the small sample size related to discipline. Reliability and applicability of data deteriorates quickly as sample size diminishes, as was seen specifically with regard to infraction rates at the gender level where each gender group n was less than 30.

In this sample, over half of all board actions resulted in loss of licensure. This study proposes no alternative as such sanctions may be the most beneficial to public safety as well as the personal welfare of the violators themselves. This is especially true given the life threatening nature of substance abuse. The over-representation of males in regard to discipline, combined with the predominance of licensure removal actions seen in this study, could denote a situation in which diversity may be impacted. However, given the comparably small over-representation of males disciplined in the study sample, this author believes that the probability of discipline producing an inadvertent impact on diversity within the CRNA population is low compared with that of the general nursing population. 


\section{Recommendations and Implications for Advanced Nursing Practice}

The area of highest priority for CRNA practice will be to raise awareness of the types of issues requiring discipline among those practicing in the anesthesia specialty of nursing. Namely, an awareness and prevention of substance abuse is critically needed. The cost of addiction and substance abuse to the practitioner is difficult to measure yet identifiable, such as time invested in education, lost salary, as well as potential physical and mental health injuries. In situations where such difficulty becomes a liability to the safety of those patients trusting CRNAs to safeguard their wellbeing and lives, the cost may be higher still. In a number of the disciplinary hearing transcripts related to unsafe practice and unprofessional conduct, substance abuse was implied, suspected, or overtly mentioned in regard to past licensing issues. It is therefore recommended that CRNA academic programs continue to stress the dangers of substance abuse as well as the benefits of prevention as a major point of education. This might include accurately identifying the scope of the problem as well as lectures by regional BON members and professionals who have lived through substance abuse and addiction. Educators may benefit from implementing preliminary drug screenings as a requirement for program entry as well as conducting random drug screenings during clinical work periods.

It may be prudent for licensing bodies to implement preliminary controlled substance testing for anyone seeking licensure. Such authorities should remain stringent in screening for any indicator of the potential for substance abuse such as prior criminal or substance abuse history and preclude such individuals for their own welfare and safety. 
Within the practice of anesthesia itself, it is critical that CRNAs be mindful of and attentive to signs of substance abuse among colleagues. Managers in particular may consider semi-regular training of staff on how to recognize and respond to signs of substance abuse in order to assist those who may be struggling with addiction to receive treatment.

It is also recommended that other advanced practice nursing specialties take steps to increase the number of males in their ranks. Doing so, would of necessity, increase the number of males in the general nursing field because it is a prerequisite for advanced practice. Advanced nursing practices may find success in recruiting males by raising awareness through promotion at college employment fairs, active work with academic counselors or even via common marketing strategies. Tuition reimbursement is another incentive that might be arranged through association work with potential employers, who in today's healthcare market find APRNs to be an asset of ever increasing value. Yet another mechanism for recruitment of specific populations, which has been successful with other minority groups, is that of scholarship and financial aid. Such financial aid can be raised and promoted through APRN professional associations themselves or lobbied for and instituted at the state or national level. As a matter of national policy, the HHS has already implemented such programs for the recruitment of nursing providers to areas and specialties of high need. It is therefore reasonable that APRN associations lobby for minor changes to such existing national policies in the interest of diversifying APRN ranks. Such policy could be altered to address males as a minority group within nursing, eligible for inclusion into such programs. It should also be noted that though such steps may increase the number of males in nursing and improve gender diversity, they may be 
met by resistance and create feelings of reverse bias. For these reasons, careful consideration should be given to weigh these possible issues against the potential benefit of such diversity initiatives in the current sociopolitical climate.

Further inquiry should be made into the national trends of CRNA discipline to solidify the findings of this initial study. Areas of risk for discipline may vary in different areas of the country, as well as gender ratios and disciplinary demographics. Such information would be valuable to state BONs, regional policy makers, and educators. Additional research into the possible impact of more balanced gender distributions on sustained diversity and improved discipline ratios should also be conducted. Such research could include other areas of healthcare where the mix of gender is either balanced or imbalanced to establish trends. If balanced gender ratios can be proven or refuted as a contributing factor to improved discipline ratios and sustained diversity, then such information could significantly impact the actions of policy makers at local and national levels. 


\section{References}

American Association of Colleges of Nursing. (2015). Enhancing diversity in the nursing workforce. Retrieved from http://www.aacn.nche.edu/media-relations/factsheets/enhancing-diversity

American Association of Nurse Anesthetists (2015). Certified registered nurse anesthetists fact sheet. Retrieved from http://www.aana.com/ceandeducation/becomeacrna/Pages/Nurse-Anesthetists-ata-Glance.aspx

Bell, D. M., McDonough, J. P., Ellison, J. S., \& Fitzhugh, E. C. (1999). Controlled drug misuse by Certified Registered Nurse Anesthetists. AANA journal, 67(2), 133140.

Benner, P., Malloch, K., Sheets, V., Bitz, K., Emrich, L., Thomas, M. B., \& Farrell, M. (2006). TERCAP: Creating a national database on nursing errors. Harvard Health Policy Review, 7(1), 48-63.

Bond, M. A., \& Haynes, M. C. (2014). Workplace diversity: a social-ecological framework and policy implications. Social Issues and Policy Review, 8(1), 167201.

Budden, J. S., Zhong, E. H., Moulton, P., \& Cimiotti, J. P. (2013). Highlights of the national workforce survey of registered nurses. Journal of Nursing Regulation, $4(2), 5-14$. 
Carter, D. A., Simkins, B. J., \& Simpson, W. G. (2003). Corporate governance, board diversity, and firm value. Financial Review, 38(1), 33-53.

Chappell, H. W., Stanhope, M., Dean, P. R., Owen, B. A., Johanson, S., Sutherland, B., \& Weisenbeck, S. M. (1999). A threat to competent and safe nursing practice. JONA'S Healthcare Law, Ethics and Regulation, 1(3), 25-32.

Evangelista, A., \& Sims-Giddens, S. (2008). Gender differences in discipline of nurses in missouri. Western Journal Of Nursing Research, 30(4), 501-514. doi:10.1177/0193945907303302

Hamza, H., \& Monroe, T. (2011). Reentry and recidivism for certified registered nurse anesthetists. Journal of Nursing Regulation, 2(1), 34-36.

Hester, M. G., Green, A., Thomas, M. B., \& Benton, M. (2011). Data analysis of Texas RNs with multiple disciplinary actions. Journal of Nursing Regulation, 2(2), 5156.

Hudson, M. L., \& Droppers, O. J. (2011). Licensed nurses disciplined in Oregon between september 1996 and june 2008. Western Journal Of Nursing Research, 33(8), 1030-1046. doi:10.1177/0193945910384491

Hudspeth, R. (2007). Survey of advanced practice registered nurses disciplinary action. Online Journal of Issues in Nursing, 12(2), 1-8.

Kenward, K. (2009). An analysis of NURSYS disciplinary data from 1996-2006. NCSBN Research Brief (39), 1-20. 
Lewis, J. D., Snodgrass, M., \& Larltin, F. H. (1990). Men in nursing: some troubling data. The American Journal of Nursing, 90(8), 30.

Lockwood, N. (2005). Workplace diversity: Leveraging the power of difference for competitive advantage. Society for Human Resource Management. Retrieved from http://www.shrm.org/research/articles/articles/pages/0605rquart_essay.aspx

National Center for Health Workforce Analysis (U.S.) (2015). Sex, race, and ethnic diversity of U.S. health occupations (2010-2012). [Bethesda, Md.]: Dept. of Health and Human Services, Health Resources and Services Administration, Bureau of Health Professions.

National Council of State Boards of Nursing. (2014). External access to NCSBN research data. Retrieved from https://www.ncsbn.org/NCSBN_Policy_107_May_2014.pdf.

Page, S. E. (2007). Making the difference: Applying a logic of diversity. The Academy of Management Perspectives, 21(4), 6-20.

Parker, R. B., Stack, S. J., Schneider, S. M., \& Summit, A. D. (2017). Why diversity and inclusion are critical to the American College of Emergency Physicians' future success.

Powers, P., Maurer, R., \& Wey, H. (2002). Characteristics of disciplined nurses [corrected] [published erratum appears in J NURS LAW 2002 Aug;8(3):6]. Journal Of Nursing Law, 8(2), 7-21. 
Roberson, Q. M., \& Park, H. J. (2007). Examining the link between diversity and firm performance the effects of diversity reputation and leader racial diversity. Group \& Organization Management, 32(5), 548-568

Smiley, R. A., \& McCarthy, C. (2016). A mixed-methods study of gender differences in nurse reporting and nurse discipline. Journal of Nursing Regulation, 7(3), 33-40.

Thomas, D. A. (2004). Diversity as strategy. Harvard Business Review, 82(9), 98-98.

Thomas, M. (2010). Registered nurses select multiple factors associated with their errors. Critical Care Nursing Clinics Of North America, 22(2), 279-282. doi:10.1016/j.ccell.2010.03.010

Thomas, R. R. (1990). From affirmative action to affirming diversity. Harvard Business Review, 68(2), 107-117.

US Bureau of Labor Statistics. (2015). Nurse anesthetists employment situation summary. Retrieved from http://www.bls.gov/oes/current/oes291151.htm

US Census Bureau. (2010). Guide to state and local census geography. Retrieved from https://www2.census.gov/geo/pdfs/reference/guidestloc/All_GSLCG.pdf

US Census Bureau. (2013). Men in nursing occupations. Industry and Occupation Statistics Branch; Social, Economic, and Housing Statistics Division; U.S. Census Bureau.

US Department of Health and Human Services. (2006). The rationale for diversity in the health professions: A review of the evidence. Health Resources and Services 
Administration, Bureau of Health Professions, ftp://ftp. hrsa. gov/bhpr/workforce/diversity. pdf.

US Department of Health and Human Services. (2011). National Healthcare Disparities Report: 2011. Washington, DC: HHS, Agency for Healthcare Research and Quality.

Waneka, R., Spetz, J., \& Keane, D. (2011). A study of California nurses placed on probation. Retrieved from https://healthforce.ucsf.edu/sites/healthforce.ucsf.edu/files/publicationpdf/probnurse.pdf

Wright, E. L., McGuiness, T., Moneyham, L. D., Schumacher, J. E., Zwerling, A., \& Stullenbarger, N. E. (2012). Opioid abuse among nurse anesthetists and anesthesiologists. AANA journal, 80(2), 121-128.

Zhong, E. H., McCarthy, C., \& Alexander, M. (2016). A review of criminal convictions among nurses 2012-2013. Journal of Nursing Regulation, 7(1), 27-33. 